\title{
FadR-Based Biosensor-Assisted Screening for Genes Enhancing Fatty Acyl-CoA Pools in Saccharomyces cerevisiae
}

Dabirian, Yasaman; Gonçalves Teixeira, Paulo; Nielsen, Jens; Siewers, Verena; David, Florian

Published in:

ACS Synthetic Biology

Link to article, DOI:

10.1021/acssynbio.9b00118

Publication date:

2019

Document Version

Peer reviewed version

Link back to DTU Orbit

Citation (APA):

Dabirian, Y., Gonçalves Teixeira, P., Nielsen, J., Siewers, V., \& David, F. (2019). FadR-Based BiosensorAssisted Screening for Genes Enhancing Fatty Acyl-CoA Pools in Saccharomyces cerevisiae. ACS Synthetic Biology, 8(8), 1788-1800. https://doi.org/10.1021/acssynbio.9b00118

\section{General rights}

Copyright and moral rights for the publications made accessible in the public portal are retained by the authors and/or other copyright owners and it is a condition of accessing publications that users recognise and abide by the legal requirements associated with these rights.

- Users may download and print one copy of any publication from the public portal for the purpose of private study or research.

- You may not further distribute the material or use it for any profit-making activity or commercial gain

- You may freely distribute the URL identifying the publication in the public portal 


\section{FadR-based biosensor assisted screening for genes enhancing fatty acyl-CoA pools in Saccharomyces cerevisiae} Yasaman Dabirian, Paulo Gonçalves Teixeira, Jens Nielsen, Verena Siewers, and Florian David ACS Synth. Biol., Just Accepted Manuscript • DOI: 10.1021/acssynbio.9b00118 • Publication Date (Web): 17 Jul 2019

Downloaded from pubs.acs.org on July 21, 2019

\section{Just Accepted}

"Just Accepted" manuscripts have been peer-reviewed and accepted for publication. They are posted online prior to technical editing, formatting for publication and author proofing. The American Chemical Society provides "Just Accepted" as a service to the research community to expedite the dissemination of scientific material as soon as possible after acceptance. "Just Accepted" manuscripts appear in full in PDF format accompanied by an HTML abstract. "Just Accepted" manuscripts have been fully peer reviewed, but should not be considered the official version of record. They are citable by the Digital Object Identifier (DOI@). "Just Accepted" is an optional service offered to authors. Therefore, the "Just Accepted" Web site may not include all articles that will be published in the journal. After a manuscript is technically edited and formatted, it will be removed from the "Just Accepted" Web site and published as an ASAP article. Note that technical editing may introduce minor changes to the manuscript text and/or graphics which could affect content, and all legal disclaimers and ethical guidelines that apply to the journal pertain. ACS cannot be held responsible for errors or consequences arising from the use of information contained in these "Just Accepted" manuscripts. 


\title{
FadR-based biosensor assisted screening for genes enhancing fatty acyl-CoA pools in Saccharomyces cerevisiae
}

\author{
Yasaman Dabirian ${ }^{1,2}$, Paulo Gonçalves Teixeira ${ }^{1}$, Jens Nielsen ${ }^{1,2,3}$ \\ Verena Siewers $^{1,2^{*}}$, and Florian David ${ }^{1,2^{*}}$
}

\begin{abstract}
${ }^{1}$ Department of Biology and Biological Engineering, Chalmers University of Technology, 41296 Gothenburg, Sweden

${ }^{2}$ Novo Nordisk Foundation Center for Biosustainability, Chalmers University of Technology, 41296 Gothenburg, Sweden

${ }^{3}$ Novo Nordisk Foundation Center for Biosustainability, Technical University of Denmark, 2800 Kongens Lyngby, Denmark
\end{abstract}

\begin{abstract}
Fatty acid-derived compounds have a range of industrial applications, from chemical building blocks to biofuels. Due to the highly dynamic nature of fatty acid metabolism, it is difficult to identify genes modulating fatty acyl-CoA levels using a rational approach. Metabolite biosensors can be used to screen genes from large-scale libraries in vivo in a

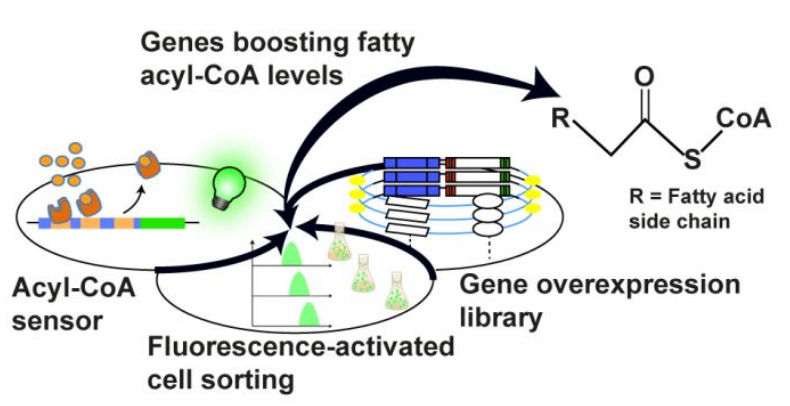
high throughput manner. Here, a fatty acyl-CoA sensor based on the transcription factor FadR from Escherichia coli was established in Saccharomyces cerevisiae and combined with a gene overexpression library to screen for genes increasing the fatty acyl-CoA pool. Fluorescenceactivated cell sorting, followed by data analysis, identified genes enhancing acyl-CoA levels. From these, overexpression of RTC3, GGA2 and LPP1 resulted in about $80 \%$ increased fatty alcohol levels. Changes in fatty acid saturation and chain length distribution could also be observed. These results indicate that the use of this acyl-CoA biosensor combined with a gene overexpression library allows for identification of gene targets improving production of fatty acids and derived products.
\end{abstract}

Keywords: Fatty acyl-CoA sensor, FadR, Saccharomyces cerevisiae, Fatty acids, Fatty alcohols 
Microbial production of industrially relevant products has been successfully established by combining various disciplines, ranging from metabolic engineering, synthetic biology to systems biology ${ }^{1-4}$. In addition, there is an interest in using large-scale libraries, such as gene overexpression $^{5}$, randomly mutated ${ }^{6}$ and genome shuffled libraries ${ }^{7}$, to identify targets that can improve production of a certain compound. The advantage of such approaches enables nonintuitive key engineering targets to be identified without a priori knowledge. The major limitation, however, is the lack of high-throughput screens necessary for evaluating such libraries, particularly if the compound of interest does not result in a clear phenotype, such as a chromophore or increased fitness.

Metabolite biosensors have shown great potential for high-throughput screening- or selection purposes ${ }^{8,9}$. A common type of biosensors in metabolic engineering applications is based on transcription factor $(\mathrm{TF}) /$ promoter pairs $^{10}$. In Saccharomyces cerevisiae, these TFbased biosensors are often based on prokaryotic repressors. This is because the transcriptional network is more complex in eukaryotes ${ }^{11}$, making the implementation of endogenous TFs as biosensor a challenging task. Employing prokaryotic TFs reduces the risk of cross-talk with other TFs or regulatory sequences, resulting in systems that are more robust and easier to work with. Prokaryotic repressors are preferred over activators because of the inherently different transcriptional systems in pro- and eukaryotes, making it difficult to integrate a prokaryotic activator into eukaryotic systems. In fact, so far only one recent study showed the successful direct implementation of prokaryotic activators as biosensors in eukaryotes ${ }^{12}$. Despite their high potential, only a limited number of synthetically constructed metabolite biosensors have been developed ${ }^{9}$. Creating a biosensor suitable for metabolic engineering applications can be challenging. For such application, it is desirable to have a broad dynamic- and operational range, which can be optimized through several approaches ${ }^{10}$. In general, the first step when constructing TF-based biosensors is to implement the binding site (BS) for the specific TF into an endogenous promoter or synthetic promoter with a desired strength. Different positions as well as different numbers of BSs need to be evaluated systematically until a desirable output level in terms of dynamic range and operational range can be achieved. The dynamic- and operational range can also be improved by fine-tuning the expression level of the TF. Following a similar strategy, biosensors responsive to e.g. malonyl-CoA ${ }^{13-15}$, naringenin or cis, cismuconic acid ${ }^{12}$ and fatty acyl-CoA ${ }^{16,17}$ have been developed.

Microbial production of fatty acids is of interest due to their use in a range of applications ${ }^{18}$. A specific challenge when improving fatty acid production is the complexity of the lipid metabolism ${ }^{19}$ and the highly dynamic and regulated metabolism of fatty acyl-CoAs ${ }^{20}$. In addition, it is challenging to engineer strains to achieve a specific fatty acid composition (saturation and chain length), which is of interest for producing desired products e.g. cocoa butter equivalents ${ }^{21}$. Although increased levels of acyl-CoA-derived compounds have been achieved in engineered strains ${ }^{22,23}$, the identification of genes that are involved in boosting acyl-CoA levels is challenging as overexpression of certain genes can be counteracted by overruling regulatory mechanisms ${ }^{24}$.

By combining an acyl-CoA responsive sensor with a gene overexpression library it is potentially possible to identify genes involved in modulating the acyl-CoA levels or the composition of the fatty acyl chains. Recently, a cDNA library from Yarrowia lipolytica was expressed in S. cerevisiae and screened for genes increasing triacylglycerol (TAG) production 
through staining with Nile Red ${ }^{25}$. Despite the successful finding of interesting targets involved in improving TAG levels, the approach does not allow one to identify targets that more specifically increases the acyl-CoA level. An acyl-CoA sensor can be developed employing the fatty acyl-CoA responsive transcription factor FadR from Escherichia coli. FadR has been reported to have a dual function in E. coli as it can act as a positive and negative regulator of genes involved in biosynthesis of unsaturated fatty acids and genes involved in fatty acid transport and beta-oxidation ${ }^{26}$, respectively. FadR is released from its BSs in the presence of fatty acyl-CoAs as binding to these results in a changed conformation, weakening its binding to DNA. It has been reported to be mainly responsive to long-chain fatty acyl-CoAs $\left(\mathrm{C}_{16}\right.$ and $\left.\mathrm{C}_{18}\right)^{27}$. Biosensors based on FadR have already been implemented for dynamic pathway regulation in bacteria ${ }^{17}$ and in yeast ${ }^{16}$ for evaluating its functionality.

Here, we established a fatty acyl-CoA specific screening system in S. cerevisiae to screen for genes increasing the fatty acyl-CoA levels employing fluorescence-activated cell sorting (FACS) (Figure 1). With our sensor, we were able to identify genes whose overexpression resulted in increased fatty acid- and/or acyl-CoA levels as well as an altered composition, which is difficult to achieve through rational engineering. This is, to our knowledge, the first time an acyl-CoA based biosensor is applied for finding genes enhancing the level of fatty acids and derived products in $S$. cerevisiae.

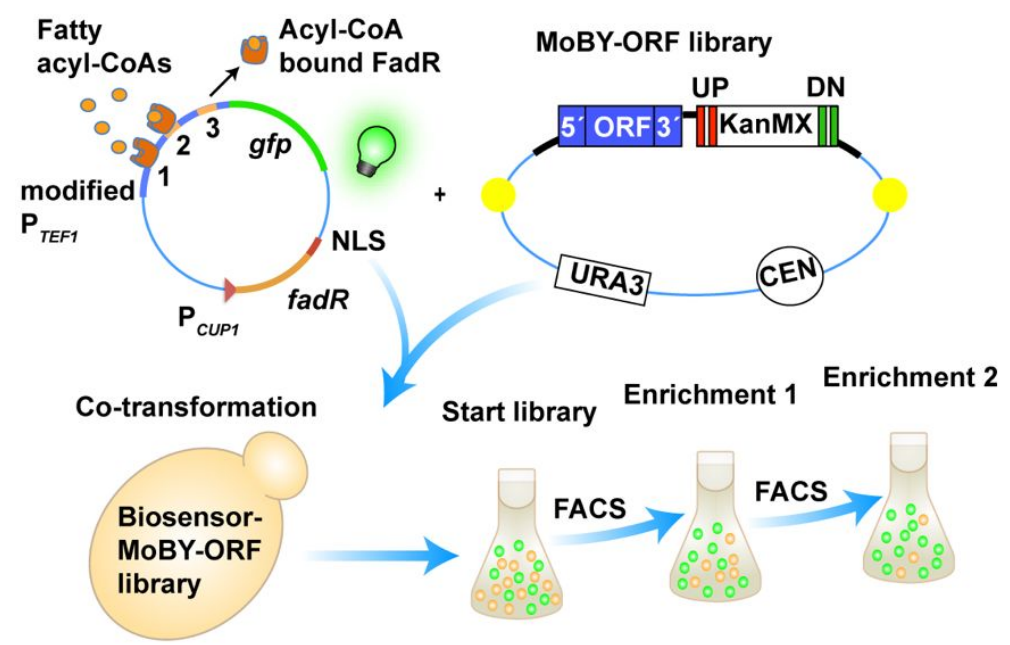

Figure 1. Screening system. The screening system is based on an acyl-CoA responsive sensor and a $S$. cerevisiae gene overexpression library (MoBY-ORF). The sensor is based on the TF FadR derived from E. coli and its BSs integrated into $\mathrm{P}_{T E F}$, which controls the expression of the output signal GFP. In the presence of acyl-CoAs, FadR is released from its BSs, resulting in increased GFP signal. $S$. cerevisiae was cotransformed with the MoBY-ORF library and the sensor plasmid, and the resulting strain library was screened for genes boosting acyl-CoA pools employing FACS in two subsequent enrichments steps. 


\section{RESULTS \\ Implementation and optimization of a fatty acyl-CoA sensor}

We established a biosensor based on the fatty acyl-CoA responsive TF FadR ${ }^{26}$ from E. coli. The sensor system was adopted for yeast by codon optimizing FadR and adding the SV40 nuclear localization signal (NLS) ${ }^{28}$ to its C-terminus to ensure transport to the nucleus. A synthetic, FadR-responsive, promoter was developed by adding its $17 \mathrm{bp} \mathrm{BS}^{29}$ sequence to the endogenous yeast promoter $\mathrm{P}_{T E F 1}$. The synthetically modified $\mathrm{P}_{T E F 1}$ promoter was coupled to GFP to allow for an output signal. Furthermore, expression of FadR was controlled by coupling it to the copper-inducible promoter $\mathrm{P}_{C U P 1}$.

To fine-tune the expression level of FadR, we first evaluated the induction capacity of the CUP1 promoter by coupling it with a GFP gene on a centromeric plasmid. Different concentrations of $\mathrm{Cu}^{2+}$ were added in the preculture samples and their effect was tested by measuring the fluorescence of main cultures grown in minimal medium, containing the same $\mathrm{Cu}^{2+}$ concentration as the precultures, 6-8 $\mathrm{h}$ after inoculation. By employing flow cytometry, we found that a concentration of $400 \mu \mathrm{M} \mathrm{Cu}^{2+}$ resulted in the highest GFP signal (Figure 2A), which is comparable with another study ${ }^{30}$ evaluating different concentrations of $\mathrm{Cu}^{2+}$.

Next, we sought to create different synthetically modified TEF1 promoters by implementing up to three FadR BSs at different locations. Through fluorescence analysis, we were able to evaluate the impact of their positions and their combinations on both the dynamicand operational range. As FadR is a prokaryotic repressor, it is considered beneficial to place the BSs in the area surrounding the TATA box and/or the transcription start site (TSS) in order to achieve repression by sterically hindering the RNA polymerase from initiating and/or elongating transcription. As implementing BSs in such area can reduce the native strength of the promoter, different numbers of BSs and their positions need to be evaluated to identify a combination that results in a suitable dynamic range. Since acyl-CoAs are endogenous metabolites that do not allow for testing of the biosensor in absence of the ligand, we here define the dynamic range as the ratio of fluorescence expression in the absence and presence of the $\mathrm{TF}$, respectively. The positions of the BSs were chosen based on a previous study were $\mathrm{P}_{T E F 1}$ was used for a similar purpose ${ }^{14}$. Briefly, the BSs were placed up- and downstream of the TSS, within $80 \mathrm{bp}$ from the start codon (Supporting Information, Sequences). The synthetically modified $\mathrm{P}_{T E F 1}$ promoters were placed upstream of a GFP gene in a centromeric plasmid, and the effect of the BSs were evaluated in presence and absence of FadR, 6-8 h after inoculation in minimal medium using shake flasks.

The native promoter strength decreased with the number of BSs and the level of repression increased in the presence of FadR (Figure 2B). Constructs with two BSs (2BS_II) and three BSs (3BS) resulted in the highest dynamic ranges of 2.3- and 3.3-fold, respectively. These were both evaluated for their responsiveness to exogenously added palmitoleic acid. The fluorescence signal increased by $12 \%$ when $0.03 \mathrm{mM}$ palmitoleic acid was added to the strain carrying the 2BS_II sensor whereas the fluorescence increased by only $5 \%$ for the strain carrying the 3BS sensor (Figure 3). This suggests that the 2BS_II sensor responds to lower concentrations of palmitoleic acid and is therefore considered to be more sensitive to fatty acids. In order to reduce the risk of false-positives during the sorting and employing a stricter selection regime to identify genes boosting the acyl-CoA pool, the 3BS sensor was selected to be used for the screening. In addition, we tested different $\mathrm{Cu}^{2+}$ concentrations, ranging from 0-650 $\mu \mathrm{M}$ 
$\mathrm{Cu}^{2+}$, using the sensor construct with $3 \mathrm{BSs}$ to evaluate whether the $400 \mu \mathrm{M} \mathrm{Cu}^{2+}$ concentration indeed resulted in the highest level of GFP repression (Supporting Information, Figure S1). Concentrations higher than $300 \mu \mathrm{M} \mathrm{Cu}^{2+}$ led to maximum repression levels of the sensor construct with 3BSs (Supporting Information, Figure S1), and we decided to proceed with the $400 \mu \mathrm{M} \mathrm{Cu}^{2+}$ concentration as this also resulted in the highest GFP expression when evaluating the CUP1 promoter coupled to GFP (Figure 2A).

A

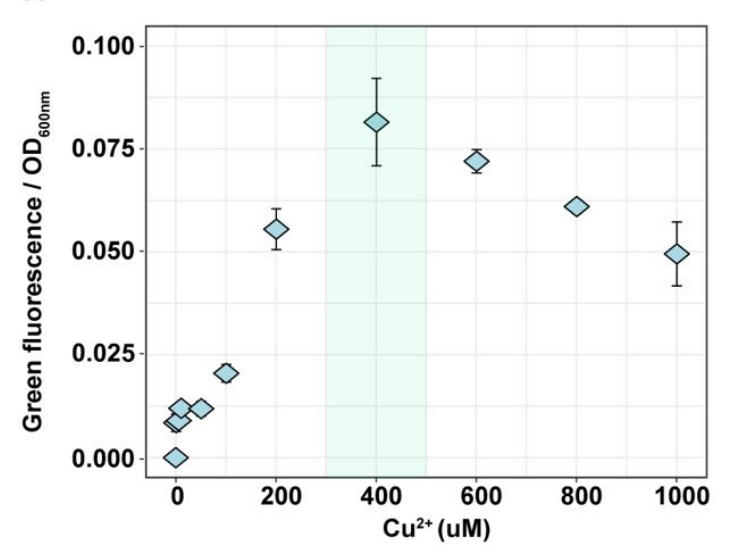

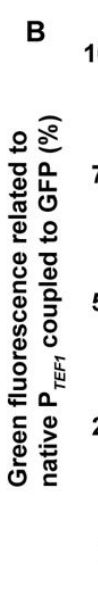

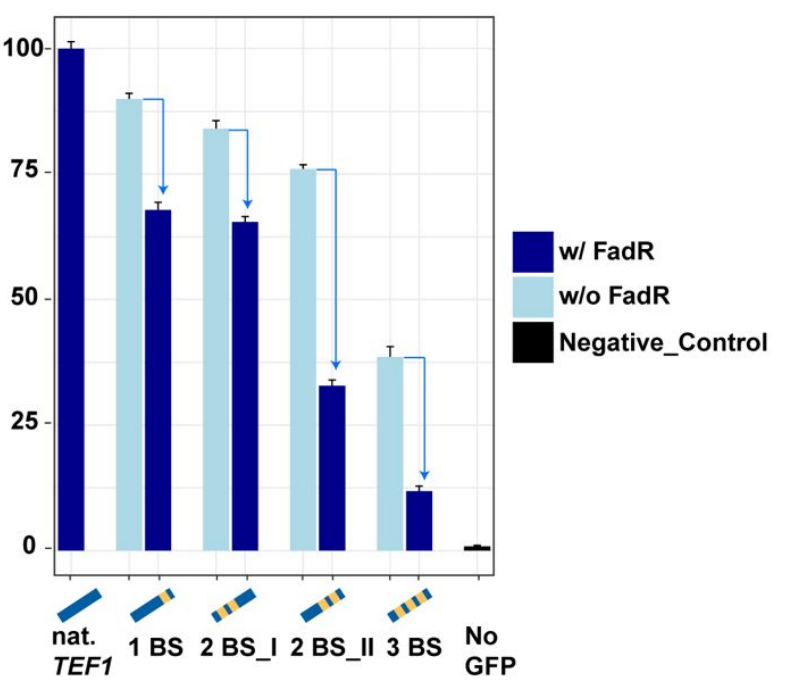

Figure 2. Sensor evaluation and optimization. A) Strain CEN.PK113-11C carrying the pCUP1-GFP plasmid was cultured at different concentrations of $\mathrm{Cu}^{2+}$ to identify the optimal inducing concentration for the CUP1 promoter. B) Different BS positions were evaluated in $\mathrm{P}_{T E F 1}$. Strains carried plasmids pSensor01 to 04 with pCUP1-FadR (w/ FadR) or with plasmid p413TEF (w/o FadR). Control strains contained plasmids pTEF1-GFP (nat. TEF1) or p416TEF (No GFP) together with p413TEF. All strains were grown in minimal medium and fluorescence measured by flow cytometry $6-8 \mathrm{~h}$ after inoculation. $\mathrm{n}=3$, error bars $= \pm$ SD.

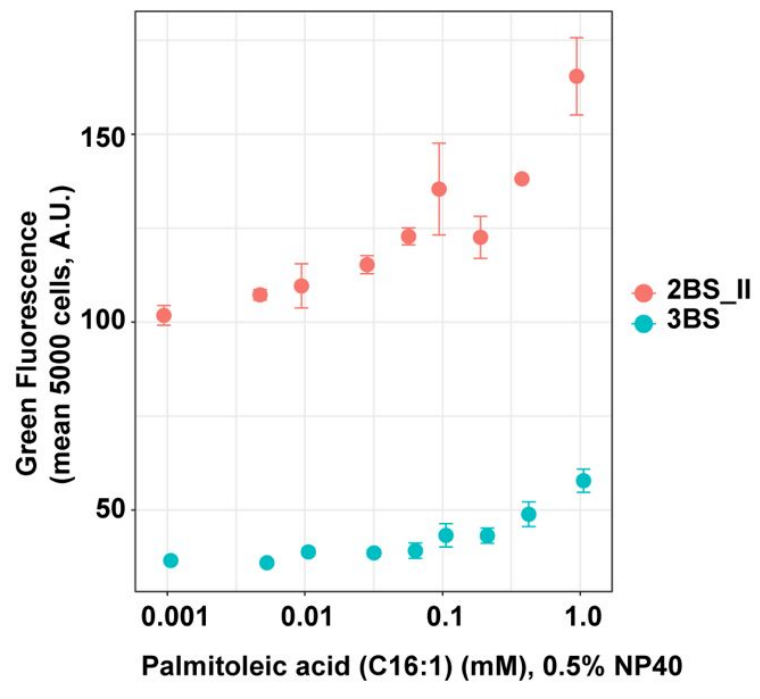

Figure 3. Sensor responsiveness. To evaluate the responsiveness of the sensor to fatty acids, palmitoleic acid was fed in different concentrations to the strains carrying plasmid pSensor03 (2BS_II) or pSensor04 (3BS) together with pCUP1FadR. Fatty acids were dissolved in Tergitol NP40 and added $3 \mathrm{~h}$ after inoculation to strains growing in minimal medium in shake flasks. Samples exposed to fatty acids were analyzed after additional $3 \mathrm{~h}$ of cultivation employing flow cytometry. $\mathrm{n}=$ 3 , error bar $= \pm \mathrm{SD}$. 


\section{Screening for candidate genes enhancing fatty acyl-CoA levels}

To screen for genes potentially increasing fatty acyl-CoA levels, the sensor was combined with a Molecular Barcoded Yeast Open Reading Frame (MoBY-ORF) ${ }^{31}$, gene overexpression, library. The MoBY-ORF library is composed of centromeric plasmids carrying each a single yeast ORF flanked by its native promoter and terminator and a pair of unique oligonucleotide barcodes (up- and downtag), comprising 4,956 genes in total. Transforming our sensor plasmid and the MoBY-ORF library resulted in around 24000 colonies, which were subjected to FACS through two subsequent enrichment steps to screen for genes boosting the fatty acyl-CoA level (Supporting Information, Figure S2). From each enrichment step, the sorted cells were collected and the unique barcode amplified as described elsewhere ${ }^{32}$. Subsequently, the barcodes were sequenced and analyzed as described in Material and Methods. The resulting read counts from enrichment 2 were plotted against the read counts from enrichment 1 . No strict cutoff was applied except for genes having less than 10 reads (in ppm) in both enrichment steps, which were excluded from further analysis (Figure 4). The starting library is reported to contain 4,956 unique genes ${ }^{31}$. Of these, 2,029 genes were still identified after the first enrichment, while the second enrichment library contained 276 genes, of which 264 genes were also present in enrichment 1 . The remaining twelve genes from enrichment 2 were below the cutoff level after enrichment 1, but were present after enrichment 2. To further evaluate the enriched libraries, a simple comparison of the GO-term distribution was performed to obtain a better understanding of associated biological processes that were enriched (Supporting Information, Figure S3). These included GO-terms with relation to transcription from RNA polymerase II promoter, ribosomal large subunit biogenesis, and ribosome assembly. As these, along with other enriched processes, such as chromatin organization and mRNA/rRNA/tRNA processing, are involved in transcription and/or translation processes, they were not further analyzed as we reasoned that these processes might contain genes that are more likely to be false-positives as there is a chance that these increase GFP expression, independent from the acyl-CoA levels. We decided to focus on genes involved in lipid metabolic processes, Golgi vesicle transport, response to oxidative stress and lipid transport. From these processes, 16 genes that were highly enriched were chosen for further evaluation. These included genes that had a high number of reads after enrichment 1, but were not present after enrichment 2 ( $A C P 1, F A A 3, O R M 1, S P O 7, T G L 1)$ as well as genes present in both libraries (MCR1, EPT1, GGA2, LPP1, INP54, GEP4, YFT2, IDP3, FAA1). The genes with the highest read counts, including MPP6 and $R T C 3$, were also chosen. The genes are labeled and marked in red (Figure 4), and their function is briefly described in Table I (and Supporting Information Table S1). 


\begin{tabular}{|c|c|c|}
\hline Gene & Description & Reference \\
\hline$A C P 1$ & Mitochondrial acyl carrier protein & $\operatorname{Ref}^{33}$ \\
\hline EPT1 & $\begin{array}{l}\text { sn-1,2-Diacylglycerol ethanolamine- and } \\
\text { cholinephosphotransferase }\end{array}$ & $\operatorname{Ref}^{34}$ \\
\hline FAA1 & Long chain fatty acyl-CoA synthetase $\left(\mathrm{C}_{12: 0^{-}}-\mathrm{C}_{16: 0}\right)$ & $\operatorname{Ref}^{35}$ \\
\hline FAA3 & Long chain fatty acyl-CoA synthetase $\left(\mathrm{C}_{16: 0^{-}} \mathrm{C}_{18: 0}\right)$ & $\operatorname{Ref}^{35}$ \\
\hline GEP4 & Mitochondrial phosphatidylglycerophosphatase & $\operatorname{Ref}^{36}$ \\
\hline GGA2 & Facilitates Golgi trafficking & $\operatorname{Ref}^{37}$ \\
\hline IDP3 & Isocitrate dehydrogenase (NADP-dependent) & $\operatorname{Ref}^{38}$ \\
\hline INP54 & Phosphatidylinositol 4,5-bisphosphate 5-phosphatase & $\operatorname{Ref}^{39}$ \\
\hline$L P P 1$ & Lipid phosphate phosphatase & $\operatorname{Ref}^{40}$ \\
\hline MCRI & Involved in ergosterol biosynthesis & $\operatorname{Ref}^{41}$ \\
\hline MPP6 & Nuclear exosome-associated RNA binding protein & $\operatorname{Ref}^{42}$ \\
\hline ORMI & Mediates sphingolipid homeostasis & $\operatorname{Ref}^{43}$ \\
\hline RTC3 & Protein of unknown function involved in RNA metabolism & $\operatorname{Ref}^{44}$ \\
\hline $\mathrm{SPO7}$ & Involved in formation of spherical nucleus & $\operatorname{Ref}^{45}$ \\
\hline TGL1 & Steryl ester hydrolase & $\operatorname{Ref}^{46}$ \\
\hline YFT2 & Required for normal ER membrane biosynthesis & $\operatorname{Ref}^{47}$ \\
\hline
\end{tabular}

Figure 4. Library analysis. The MoBY-ORF library contains 4,956 uniquely barcoded ORFs of S. cerevisiae. Two subsequent enrichment steps were performed of the combined biosensor-MoBY-ORF library by employing FACS. The left panel illustrates the number of unique genes identified in each of the libraries. In the right panel, the read counts for the genes identified in enrichment library 1 and/or 2 are plotted against each other. For each gene, the reads were normalized to the total number of reads in the library (in ppm).

Table I. List of candidate genes and their function 


\section{Evaluation of candidate genes through fatty acid analysis}

To evaluate the impact of the chosen genes on fatty acid production, the genes were integrated into the genome of strain IMX581 under the control of the TEF1 promoter. Subsequently, the growth behavior of these strains was analyzed via a Growth profiler, in minimal medium supplemented with $60 \mathrm{mg} / \mathrm{L}$ uracil. The maximum specific growth rates in both the glucoseand ethanol phase as well as the diauxic shift duration were calculated (Supporting Information, Figure S4). Strains overexpressing the genes RTC3, GGA2, IDP3, and LPP1 showed changes in their growth phenotypes compared to IMX581. Overexpression of RTC3 resulted in a severe growth defect. Overexpression of $G G A 2$ resulted in a shorter diauxic shift duration whereas for strains overexpressing IDP3 and $L P P 1$ the duration was longer.

For the fatty acid analysis, the strains were grown in minimal medium supplemented with $60 \mathrm{mg} / \mathrm{L}$ uracil in shake flasks. The total fatty acid levels were quantified from samples harvested $8 \mathrm{~h}$ and $48 \mathrm{~h}$ after inoculation. Since the cell sorting had been performed in the glucose phase, 6-8 $\mathrm{h}$ after inoculation, we decided to measure the fatty acid levels in this phase as well as after $48 \mathrm{~h}$ in order to evaluate whether the effect of the genes would keep the same trend throughout this time. This is because the fatty acid metabolism differs during growth on glucose and ethanol, respectively, and therefore the effects resulting from overexpression of the target genes may also differ.

The fatty acid levels for the control strain IMX581 of about $30 \mathrm{mg} / \mathrm{gDCW}$ after $48 \mathrm{~h}$ were comparable to the results of a previous study using the same parental $\operatorname{strain}^{21}$ (Figure 5). Significant ( $p$-value $<0.05$ or $p$-value $<0.01$ ) increases in fatty acid levels were observed for the strains overexpressing GGA2 and $T G L 1$, although the effect of overexpressing $T G L 1$ was only seen in the sampling time point after $48 \mathrm{~h}$. The effect of overexpressing GGA2 was seen at both sampling time points and resulted in $30 \%$ and $24 \%$ increased fatty acid levels (Figure 5A). This effect was mainly due to a significant increase $(p$-value $<0.01)$ in the $\mathrm{C}_{16: 1}$ and $\mathrm{C}_{16: 0}$ fatty acid levels (Figure 5B-C), as also seen in the percental composition analysis (Supporting Information, Figure S5). A similar pattern in redistribution of fatty acid chain length was also observed for the strain overexpressing IDP3 (Figure 5B-C, and Supporting Information, Figure S5), although no overall increase in the total fatty acid levels was observed (Figure 5A). Another candidate gene whose expression did not result in increased total levels, but resulted in significant changes in the fatty acid composition, was RTC3. The $\mathrm{C}_{18}$ levels were significantly $(p$-value $<0.05$ or $p$-value $<0.01)$ increased whereas the $\mathrm{C}_{16}$ levels were significantly decreased ( $p$-value $<0.01$ ) (Figure 5C, and Supporting Information, Figure S5B). When analyzing the changes in the ratio of $\mathrm{C}_{18}$ and $\mathrm{C}_{16}$, the majority of the candidate genes led to a decreased $\mathrm{C}_{18}$ to $\mathrm{C}_{16}$ ratio in the glucose phase, especially the genes GGA2 and IDP3 (Supporting Information, Figure S8A). However, for the samples taken after $48 \mathrm{~h}$, this trend could not be seen except for strains carrying ACP1, INP54, MPP6, EPT1, GEP4, FAA1, IDP3 and $G G A 2$ (Supporting Information, Figure S8B). 


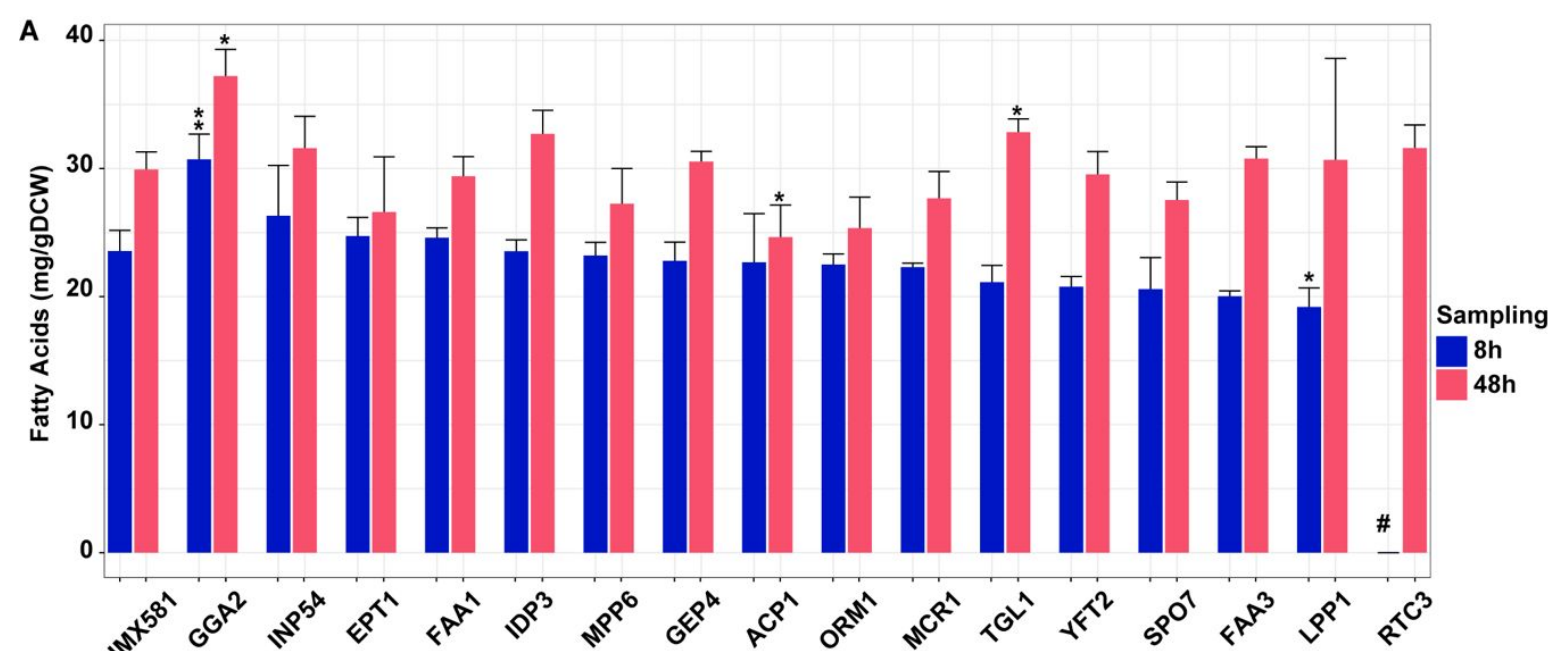

B
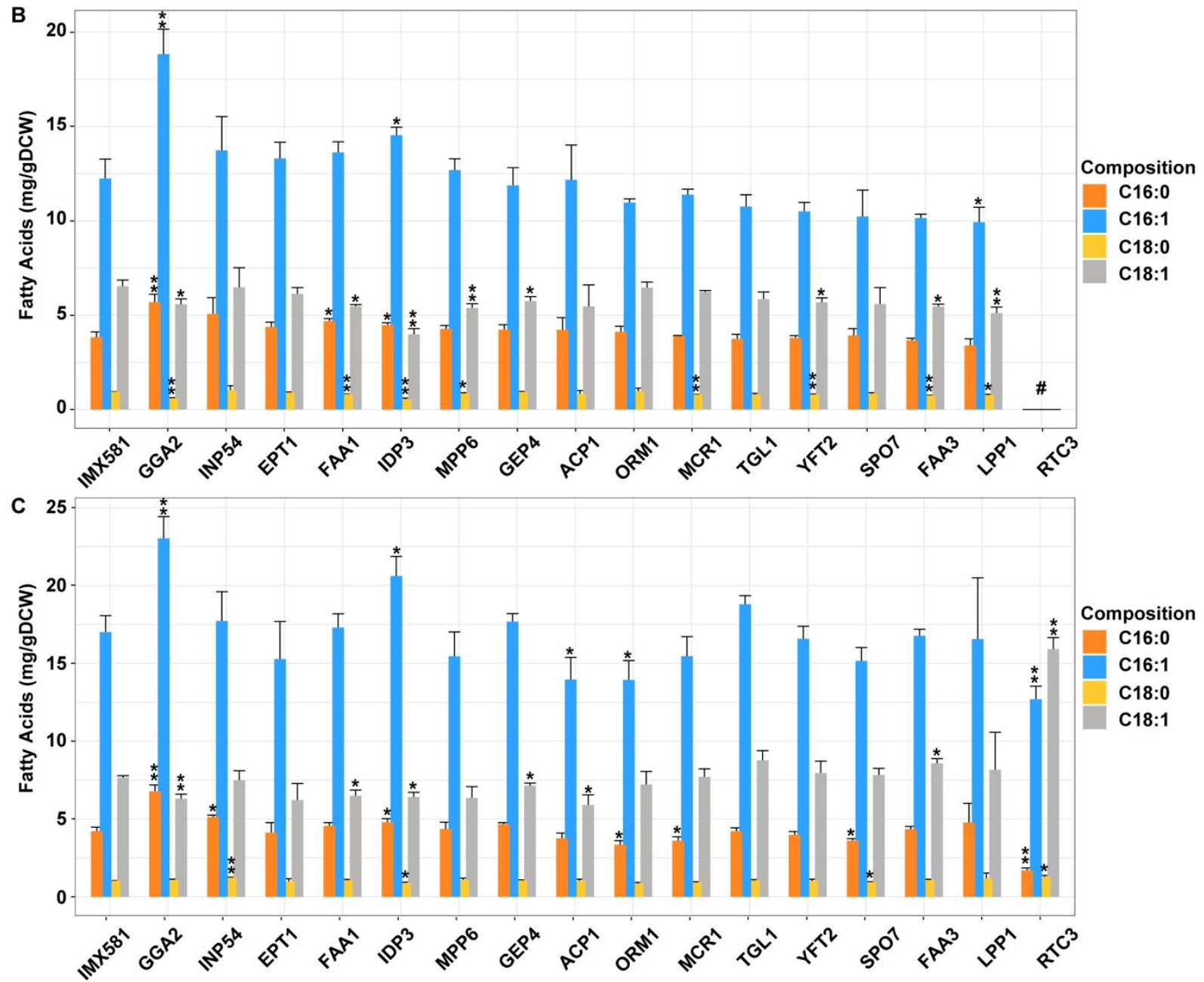

Figure 5. Fatty acid analysis. A) Total fatty acids of strains YDA001 to YDA016 as well as control IMX581 measured $8 \mathrm{~h}$ (blue bar) and $48 \mathrm{~h}$ (red bar) after inoculation. B) Composition of fatty acids after $8 \mathrm{~h}$, and C) $48 \mathrm{~h}$. Strains were grown in minimal medium supplemented with $60 \mathrm{mg} / \mathrm{L}$ uracil. \# Not measured due to slow growth. $\mathrm{n}=3$, error bars $= \pm \mathrm{SD}$. ${ }^{*} p$ value $<0.05, * * p$-value $<0.01$ (student's t-test).

Evaluation of candidate genes through fatty alcohol analysis 
As the acyl-CoA levels are highly regulated, it is not certain that an increase in acyl-CoA levels would also lead to an increase of total fatty acid accumulation. A way to evaluate increases in the acyl-CoA pool, and increased flux towards this pool, is converting it to fatty alcohols using a fatty acyl-CoA reductase (FAR), thereby creating a metabolic pull and accumulation of an end product that is easily measured. As FadR is mainly sensitive to long-chain fatty acyl-CoAs $\left(\mathrm{C}_{16} \text { and } \mathrm{C}_{18}\right)^{27}$, we sought to use an acyl-CoA reductase that is specific for these chain lengths. In this study, two fatty acyl-CoA reductases were evaluated in our background strain IMX581, one derived from Apis mellifera ${ }^{48}$ and one from Marinobacter aquaeolei VT8 (Maqu_2220) ${ }^{49}$. Expression of the reductase from M. aquaeolei (pMaFAR) resulted in more than 11-fold higher fatty alcohol production compared to the one from A. mellifera (pAmFAR) (Supporting Information, Figure S6). Furthermore, we were able to observe production of $\mathrm{C}_{18: 1}-\mathrm{OH}$ and $\mathrm{C}_{16: 1} \mathrm{OH}$ fatty alcohol, which could not be observed after expressing AmFAR (Supporting Information, Figure S6). The majority of the fatty alcohols were saturated despite the higher proportion of unsaturated fatty acids observed from the fatty acid analysis (Figure 5). Therefore, we found MaFAR a better candidate for sensing variations in the acyl-CoA pool and used expression of this enzyme for further evaluating the genes. The strains used for fatty acid analysis were also used to evaluate the fatty alcohol production after transforming these strains with a centromeric plasmid for MaFAR expression.

The fatty alcohol measurements were performed on samples harvested $72 \mathrm{~h}$ after inoculation in shake flasks with minimal medium. As the reductase converts acyl-CoAs to fatty alcohols through an irreversible reaction, we decided to only evaluate accumulative fatty alcohol levels, assuming that these will not be consumed through other reactions. From the genes evaluated, $R T C 3, L P P 1$, and $G G A 2$, resulted in around $80 \%$ increased fatty alcohol levels $(p$-value $<0.01)$ (Figure 6A) and changes in fatty alcohol composition (Figure 6B). Overexpression of the gene RTC3 resulted in significantly increased $\mathrm{C}_{18}-\mathrm{OH}$ levels ( $p$ value $<0.01$ ) whereas the $\mathrm{C}_{16}-\mathrm{OH}$ levels were not significantly changed. The total level of increased $\mathrm{C}_{18}-\mathrm{OH}$ compared to the $\mathrm{C}_{16}-\mathrm{OH}$ levels can also be seen in the ratio analysis (Supporting Information, Figure S8C). From the analysis of the GGA2 overexpressing strain, the $\mathrm{C}_{16}-\mathrm{OH}$ and $\mathrm{C}_{18}-\mathrm{OH}$ levels were significantly increased ( $p$-value $<0.05$ or $p$-value $<0.01$ ) (Figure $6 \mathrm{~B}$ ). However, the percental changes of $\mathrm{C}_{16: 0^{-}} \mathrm{OH}$ was decreased and the $\mathrm{C}_{18: 0^{-}} \mathrm{OH}$ was increased compared to IMX581 (Supporting Information, Figure S7). For the strain overexpressing IDP3, the $\mathrm{C}_{16: 1}-\mathrm{OH}$ level was significantly decreased ( $p$-value $<0.01$ ) whereas the $\mathrm{C}_{18: 0}-\mathrm{OH}$ level was increased ( $p$-value $<0.05$ ) (Figure 6). Although overexpression of $L P P 1$ did not result in increased fatty acid levels (Figure 5A) it resulted in significantly $(p$-value $<0.01$ ) increased fatty alcohol levels (Figure 6) as well as changed composition (Figure 6b). 


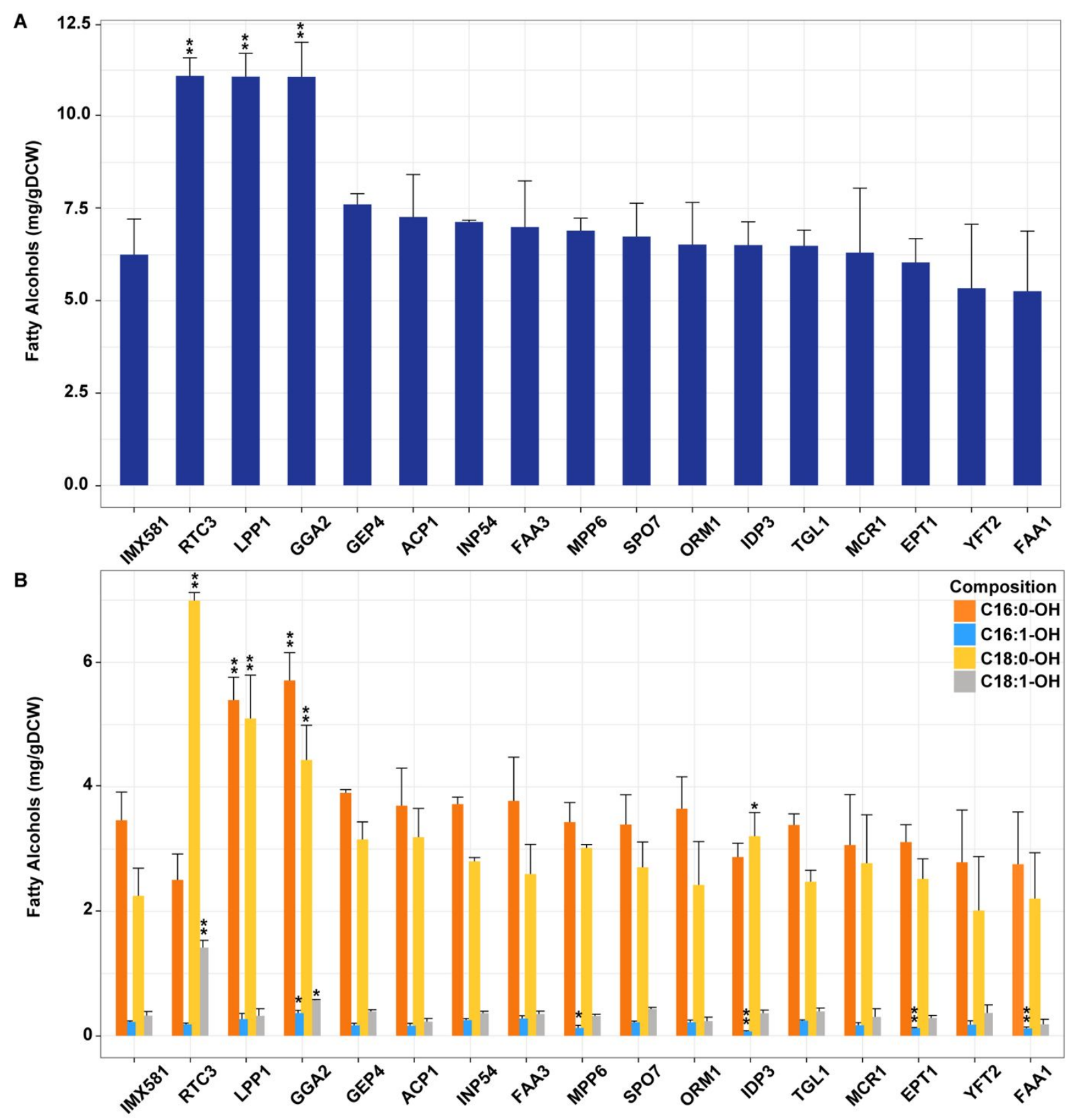

Figure 6. Fatty alcohol analysis. A) Total fatty alcohol levels were evaluated in strains YDA001 to YDA016 containing plasmid pMaFAR. B) Composition of fatty alcohols. Strains were grown in minimal medium and samples were harvested $72 \mathrm{~h}$ after inoculation. $\mathrm{n}=3$, error bars $= \pm \mathrm{SD} . * p$-value $<0.05, * * p$-value $<0.01$ (student's t-test).

\section{DISCUSSION}


Rationally engineering strains to produce a certain compound can be time-consuming as it is often performed according to the trial-and-error principle. As more high-throughput screens are being developed, it is becoming easier and faster to identify novel engineering targets out of large strain libraries. The combination of a fatty acyl-CoA sensor with a gene overexpression library allows for screening of candidate genes that are not intuitively known to enhance the acyl-CoA level. Using this approach, we here identified genes, including RTC3, GGA2 and $L P P 1$, that have not previously been reported to improve/change the acyl-CoA level and composition. Although an acyl-CoA sensor based on FadR from E. coli has previously been employed for dynamically regulating metabolic pathways in E. coli ${ }^{17}$, and evaluated in $S$. cerevisiae as a potential metabolite biosensor for dynamic pathway regulation ${ }^{16}$, it has, to our knowledge, not been employed in $S$. cerevisiae for the screening of strain libraries.

To improve the dynamic range of the biosensor, we used the inducible promoter $\mathrm{P}_{C U P I}$ and tested different concentrations of $\mathrm{Cu}^{2+}$ that resulted in an optimal expression of the TF FadR. Although $\mathrm{Cu}^{2+}$ is an inducer that is toxic to yeast cells at higher concentrations ${ }^{50}$, copper regulation allows one to identify a desirable expression level of the TF, which is one way to change the dynamic and/or operational range of the sensor. Furthermore, different numbers of FadR binding sites integrated at different locations within the core promoter of TEF1 were evaluated to determine the combination that resulted in the highest dynamic range. To minimize the risk of enriching for false-positive cells, we decided to apply the sensor with three binding sites thus applying a higher stringency to increase the chances to find candidate genes that resulted in clearly increased acyl-CoA levels.

By combining the gene overexpression library, MoBY-ORF, with our established acylCoA sensor, we were able to screen for genes enhancing the acyl-CoA levels. The effect of the candidate genes was analyzed by measuring the fatty acid- as well as the fatty alcohol levels. As the fatty acid metabolism in its native state is highly dynamic, a more direct way to measure any increase in acyl-CoA levels is to use a reductase that converts acyl-CoA to fatty alcohols through an irreversible reaction. Overexpression of three out of the 16 genes selected after two rounds of library enrichment and sequencing indeed led to increased fatty alcohol levels. There are several possible reasons why this was not seen for overexpression of the remaining genes. First, effects not related to increased acyl-CoA levels may have resulted in increased fluorescence of these cells as indicated also by the observation that many of the sorted genes belonged to GO-terms related to transcription and translation. Second, the strain libraries were sorted during exponential growth while fatty alcohol production was assessed cumulatively over the entire culture time. Therefore, potential temporary increases in acyl-CoA levels at the time of cell sorting may not reflect in overall increased fatty alcohol concentrations. Third, the sensor may not have responded to overall increased acyl-CoA levels but due to differential affinity to an increase of certain species. An indication for this could be the decreased $\mathrm{C}_{18} / \mathrm{C}_{16}$ fatty acid ratio in several of the overexpression strains during exponential growth such as the strain overexpressing IDP3. Finally, prior to analyzing the strains for fatty acid/alcohol production, the candidate genes were placed under the TEF1 promoter, whereas the genes in the overexpression library were placed under their native promoter. Therefore, a strong promoter like TEF1 may in some cases have resulted in less optimal conditions thereby preventing improved production. 
An interesting observation was also that for several of the strains, trends seen for the total fatty acid analysis differed from the results on fatty alcohol production. For example, while overexpression of RTC3 increased the levels of both $\mathrm{C}_{18}$ fatty acids and $\mathrm{C}_{18}-\mathrm{OHs}$ and $G G A 2$ overexpression the levels of $\mathrm{C}_{16}$ fatty acids and alcohols, the $L P P 1$ overexpression strain showed increased levels of saturated fatty alcohols, which was not reflected in the fatty acid profile. In general, the overall composition profile of $\mathrm{C}_{18}$ and $\mathrm{C}_{16}$ species was different between the two analyses with a higher proportion of saturated species in the fatty alcohols than in the total fatty acids. MaFAR has been reported to have highest activity in generation of $\mathrm{C}_{18: 1} \mathrm{OH}$ followed by $\mathrm{C}_{18: 0^{-}} \mathrm{OH}^{49}$, and therefore its expression was expected to result in higher levels of $\mathrm{C}_{18: 1} \mathrm{OH}$ than what was observed in this study. The reason for why this was not the case could be potential competition of MaFAR with other enzymes of lipid metabolism that may have a higher affinity for $\mathrm{C}_{18: 1}$ acyl-CoA or a lower affinity for $\mathrm{C}_{18: 0}$ acyl-CoA. It has been shown that competition between desaturase Ole1p and acyltransferase Sctlp changes the overall lipid profile ${ }^{51}$, and in our study a similar case might be the reason for the changed profile in the fatty alcohol analysis compared to the fatty acid analysis and why we do not see higher levels of $\mathrm{C}_{18: 1} \mathrm{OH}$ levels despite the higher in vitro activity of MaFAR toward this species.

The genes RTC3, GGA2 and LPPI whose overexpression resulted in increased production of fatty alcohols, have not been reported previously to be directly involved in increasing the fatty acyl-CoA levels. The function and mechanism of Rtc3p is still not well understood and the protein has so far not been extensively studied. The gene was named RTC (restriction of telomere capping) in a previous study since its deletion was able to suppress the phenotype of the temperature-sensitive $c d c 13-1$ mutant $^{44}$. $C D C 13$ is involved in telomer capping. An earlier study identified that its protein sequence shares structural similarities with the human protein SBDS involved in the Shwachman-Bodian-Diamond syndrome. This protein and its homologues, including Rtc3p, are believed to play a role in RNA metabolism ${ }^{52}$. As Rtc3p has been suggested to be involved in quite different mechanisms, and we also observed a severe growth defect when overexpressing it, its effect on fatty acid metabolism may well be of indirect nature.

In contrast, Gga2p, a monomeric clathrin adaptor protein, has been studied in more detail and is reported to play an important role in Golgi trafficking ${ }^{53}$. It seems to function through interaction with phosphoinositide, which represent a family of lipids and play an important role in maintaining proper functioning of the Golgi apparatus ${ }^{54}$. Gga2p has been reported to bind to phosphatidylinositol 4-kinase, Pik1p, and through this interaction localize this kinase to the trans-Golgi network (TGN), where Pik1p synthesizes phosphatidylinositol 4-phosphate (PI(4)P). In other words, Gga2p is reported to regulate the synthesis of PI(4)P upon interacting with phosphoinositides ${ }^{55,56}$. PI(4)P plays also a role in recruiting Gga2p to the Golgi. Mutations inhibiting the interaction between Gga2p and Pik1p resulted in delayed localization of Pik1p to TGN, leading to delayed accumulation of PI(4) $\mathrm{P}^{55,57}$. Furthermore, overexpression of Pik1p resulted in increased PI(4)P levels as well as increased localization of Gga2p to the TGN, indicating a positive-feedback loop ${ }^{57}$. A hypothetical mechanism explaining the increased fatty acid levels observed in our study from overexpressing Gga2p could be that increased levels of Gga2p results in increased levels of PI(4)P. An increase of PI(4)P would decrease the PI pool, leading to enhanced PI synthesis, which would in turn reduce inositol levels. Since many fatty acid synthesis genes have UAS $\mathrm{INO}_{\mathrm{INO}}$ elements in their promoter, reduced inositol levels would 
lead to increased gene expression of fatty acid biosynthetic genes ${ }^{58}$. This could be further investigated by looking at the transcript levels of these genes.

Among the top three candidate genes found to boost the acyl-CoA levels, LPPI is most closely reported to be involved in lipid metabolism ${ }^{40}$. Although the overexpression of $L P P 1 \mathrm{did}$ not result in any increased total fatty acid levels nor in any specific changes in fatty acid composition, it was one of the top candidates in the fatty alcohol analysis. This could mean that $L P P 1$ is only revealed as a promising candidate when applying a pull, meaning that its effect is accumulated over time. Lpp1p is a lipid phosphate phosphatase that is involved in the regulation of phospholipid metabolism. It is reported to be involved in the dephosphorylation of phosphatidic acid (PA) to diacylglycerol (DAG). DAG can be converted to TAG, and further degraded to free fatty acids ${ }^{59}$, which are subsequently activated to acyl-CoAs ${ }^{35}$. In our case, increased fatty alcohol levels were observed after measurement from a $72 \mathrm{~h}$ culture, which might indicate that fatty alcohols were accumulated over time, possibly due to an increased flux through the acyl-CoA pool. A hypothetical explanation for this could be that the flux from PA is pushed towards TAG synthesis, from which free fatty acids can be derived that are then activated to acyl-CoAs. A strategy using increased flux through TAG in order to increase free fatty acid levels has previously been shown ${ }^{60}$.

Further studies are necessary to reveal the specific mechanisms of the identified genes and their role in influencing the acyl-CoA level and/or profile. To further evaluate the effect of these genes in metabolic engineering applications, one could implement these also in strains already engineered for increased fatty acid/alcohol production. Due to the complexity of fatty acid metabolism it is, however, difficult to anticipate potential additive or synergistic effects and the effect from overexpressing any of these genes might be masked in a highly engineered strain. For instance, while inhibition of beta-oxidation as sole strategy was shown to increase production of fatty-acid derived products ${ }^{61}$, this effect was not seen in a highly engineered background strain ${ }^{59}$.

In conclusion, we here demonstrated that combination of metabolite biosensors and gene overexpression libraries is an attractive and fast way to identify novel gene targets. This has applications for both metabolic engineering, where genes modulating the acyl-CoA levels and composition can be identified, and for fundamental studies where genes involved in influencing the fatty acid metabolism can be uncovered and further evaluated to gain a better understanding of their mechanism. The genes identified in this study have not previously been reported to influence the acyl-CoA pool, suggesting that our approach to combine a fatty acylCoA sensor with a gene overexpression library to reveal new target genes is promising.

\section{MATERIAL AND METHODS}

\section{Chemicals and Reagents}

All oligonucleotide primers were synthesized at Eurofins. Restriction enzymes, DNA gel extraction- and plasmid purification kits were purchased from Thermo Fischer Scientific. The Gibson Assembly ${ }^{\circledR}$ Master mix was purchased from New England Biolabs. PrimeStar DNA polymerase was purchased from TaKaRa Bio. All reagents used for media preparation were purchased from Merck Millipore unless otherwise noted. $\mathrm{N}, \mathrm{O}$ Bis(trimethylsilyl)trifluoroacetamide (BSTFA), palmitoleic acid (98.5\%) and copper(II) sulfate 
pentahydrate were purchased from Sigma-Aldrich. Frozen-EZ Yeast Transformation II Kit and Zymoprep Yeast Plasmid Miniprep Kits were purchased from Zymo Research.

\section{Strains}

S. cerevisiae strain CEN.PK113-11C (MATa SUCMAL2-8c his3A1 ura3-52) ${ }^{62}$ was used as the background strain for co-transformation of the MoBY-ORF library ${ }^{31}$ and the acyl-CoA sensor. S. cerevisiae strain IMX581 (MATa ura3-52 can1A::cas9-natNT2 TRP1 LEU2 HIS3) ${ }^{63}$, derived from the parental strain CEN.PK113-5D, was used as the background strain for genomic integration and evaluation of selected genes. For standard cloning procedures, competent $E$. coli cells, DH5 $\alpha$, were routinely used.

\section{Media}

YPD medium, containing $10 \mathrm{~g} / \mathrm{L}$ yeast extract, $20 \mathrm{~g} / \mathrm{L}$ casein peptone and $20 \mathrm{~g} / \mathrm{L}$ glucose, was used when preparing yeast competent cells. For selection of yeast transformants carrying URA3- and HIS3-based plasmids, synthetic complete medium plates without uracil and histidine (SC-URA-HIS) containing $6.7 \mathrm{~g} / \mathrm{L}$ yeast nitrogen base (YNB) without amino acids, $0.77 \mathrm{~g} / \mathrm{L}$ complete supplement mixture without uracil and histidine (CSM-URA-HIS), $20 \mathrm{~g} / \mathrm{L}$ agar and $20 \mathrm{~g} / \mathrm{L}$ glucose were used. Similarly, SC-URA plates were used for selecting yeast strains carrying URA3-based plasmids. Plates containing $6.7 \mathrm{~g} / \mathrm{L} \mathrm{YNB}, 0.77 \mathrm{~g} / \mathrm{L}$ CSM and 0.8 $\mathrm{g} / \mathrm{L} \mathrm{g}$ 5-fluoroorotic acid (5-FOA) were routinely used to select against the URA3-based gRNA plasmid. For sensor evaluation, yeast strains were cultured in defined minimal medium ${ }^{64}$ containing $7.5 \mathrm{~g} / \mathrm{L}\left(\mathrm{NH}_{4}\right)_{2} \mathrm{SO}_{4}, 14.4 \mathrm{~g} / \mathrm{L} \mathrm{KH}_{2} \mathrm{PO}_{4}, 0.5 \mathrm{~g} / \mathrm{L} \mathrm{MgSO} \mathrm{M}_{4} \cdot 7 \mathrm{H}_{2} \mathrm{O}, 20 \mathrm{~g} / \mathrm{L}$ glucose, 2 $\mathrm{mL} / \mathrm{L}$ trace metal- and $1 \mathrm{~mL} / \mathrm{L}$ vitamin solution ${ }^{64}$. The $\mathrm{pH}$ was adjusted to 6.5 with $\mathrm{KOH}$. For fatty acid and fatty alcohol analysis, $5 \mathrm{~g} / \mathrm{L}\left(\mathrm{NH}_{4}\right)_{2} \mathrm{SO}_{4}$ was used instead of $7.5 \mathrm{~g} / \mathrm{L}$ and for fatty acid analysis the medium was supplemented with $60 \mathrm{mg} / \mathrm{L}$ uracil. For culturing $E$. coli cells, lysogenic broth (LB) supplemented with $100 \mathrm{mg} / \mathrm{L}$ ampicillin was used.

\section{Culture Conditions}

For flow cytometry analysis, main cultures were inoculated from $24 \mathrm{~h}$ precultures at an $\mathrm{OD}_{600}$ of $0.1 \mathrm{in} 10 \mathrm{~mL}$ medium in $100 \mathrm{~mL}$ shake flasks, and fluorescence was measured $6-8 \mathrm{~h}$ after inoculation. The optimal concentration of $\mathrm{Cu}^{2+}$ induction was evaluated by adding different concentrations of $\mathrm{Cu}^{2+}$ in the pre-culture and analyzing samples from main cultures, which contained the same concentration of $\mathrm{Cu}^{2+}$ as the pre-cultures. A concentration of $400 \mu \mathrm{M} \mathrm{Cu}^{2+}$ was used for further experiments. For fatty acid feeding, a stock solution of $20 \mathrm{mM}$ palmitoleic acid was prepared by dissolving it in Tergitol NP40. The cultures were fed with different concentrations of palmitoleic acid $3 \mathrm{~h}$ after inoculation and samples were measured employing flow cytometry after additional cultivation for $3 \mathrm{~h}$. For fatty acid and fatty alcohol analysis, main cultures were inoculated, from $48 \mathrm{~h}$ precultures, at an $\mathrm{OD}_{600}$ of 0.1 in $25 \mathrm{~mL}$ medium in $100 \mathrm{~mL}$ shake flasks. To analyze the growth of the engineered strains carrying the candidate genes, cultures were inoculated, from $48 \mathrm{~h}$ precultures, to an $\mathrm{OD}_{600} 0.1$ in $250 \mu$ l final volume at rpm 250 in a 96-well microtiter plate. Growth was monitored using a growth profiler (EnzyScreen). S. cerevisiae strains and E. coli cells were cultured at standard conditions, $30^{\circ} \mathrm{C}$ and $37^{\circ} \mathrm{C}$, respectively. 


\section{Plasmid and Strain Construction}

All primer sequences and sequences of ordered genes/fragments used in this study are listed in Supporting Information. All plasmids and strains used in this study are listed in Table 2 and Table 3. In plasmid pTEF1-GFP, constructed previously ${ }^{14}$, modified parts of the TEF1 promoter (BS1/2/3) carrying different FadR BS combinations were introduced (Supporting Information, Sequences). These were ordered from Genscript and were amplified using the primer pair pFDA13/14. The vector backbone of p416TEF1-GFP was amplified using primers pFDA15/16, creating overlapping regions with the modified TEF1 promoter fragments. Subsequently, the plasmids pSensor01-04 were constructed using the CPEC cloning method ${ }^{65}$. To create the plasmid pCUP1-FadR, the CUP1 promoter was amplified from S. cerevisiae genomic DNA with primers pFDA01/02, fadR (sequence including an NLS signal was codonoptimized for expression in $S$. cerevisiae and ordered from Genscript) was amplified using primer pair pFDA03/04 and the vector backbone p413TEF was amplified using primer pair pFDA05/06, thereby creating regions that overlapped with the amplified CUP1 promoter and the amplified $f a d R$ fragment. Similarly, the plasmid pCUP1-GFP was constructed using primer pair pFDA07/08 for amplifying CUP1 promoter, pFDA09/10 for the GFP gene and pFDA11/12 for vector backbone amplification. The BS3-GFP cassette from pSensor04 was amplified using the primer pair pFDA17/18 and cloned with the pCUP1-FadR backbone amplified by pFDA19/20 via ligation, thereby creating pSensor05. Background strain CEN.PK113-11C was co-transformed with sensor plasmid pSensor05 and the MoBY-ORF centromeric library using the Frozen-EZ Yeast Transformation II Kit (Zymo Research) resulting in about 24000 colonies, corresponding to an almost 6 times coverage of the library.

The selected genes, promoters and terminators were all amplified from the genomic DNA of IMX581. The genes were integrated into integration site $X \_3^{66}$ in the background strain IMX581. The overlapping homologous regions were amplified using primers pairs $\mathrm{pYDA01/02}$ for the upstream region and primer pair $\mathrm{pYDA03/04}$ for the downstream region. Promoter $\mathrm{P}_{T E F 1}$ and terminator $\mathrm{T}_{C Y C l}$ were used for controlling gene expression of all selected genes. $\mathrm{P}_{T E F I}$ was amplified using primers pYDA05/06 and $\mathrm{T}_{C Y C l}$ was amplified using primer pairs pYDA07/08. All genes were amplified using their corresponding primers, pYD16-pYDA47. Amplified genetic parts, including homologous regions and promoter-gene-terminator, were assembled into a cassette through a two-step fusion PCR procedure adapted from ${ }^{67}$. The cassettes were used to transform the background strain together with the gRNA plasmid pQC005 using the yeast transformation protocol ${ }^{68}$. The gRNA plasmid, based on the backbone plasmid pMEL10 was constructed following the method described elsewhere ${ }^{63}$, and was subsequently removed by plating on 5-FOA plates. The resulting strains carrying the genes were named YDA001YDA016.

To construct plasmid $\mathrm{pAmFAR}, \mathrm{P}_{P G K l}$ was amplified using primers pairs $\mathrm{pYDA09/10}$ and AmFAR was amplified using primer pairs pYDA12/13. Plasmid p416TEF was used as the backbone and was digested with the restriction enzymes BamHI and SacI such that $\mathrm{P}_{T E F I}$ was removed and the linearized backbone was assembled with $\mathrm{P}_{P G K l}$ and $A m F A R$ using the Gibson Assembly ${ }^{\circledR}$ Master mix. Similarly, plasmid pMaFAR was constructed using primer pairs pYDA10/11 to amplify $\mathrm{P}_{P G K 1}$ and primers pYDA14/15 to amplify MaFAR. All plasmid constructs were verified through sequencing at Eurofins. Insertion of the genes in the background strain IMX581 were verified through colony PCR using primer pair pYDA48/49. 
The PCR products were purified using PCR Purification Kit (Thermo Fischer Scientific) and subsequently sequenced to ensure absence of mutations.

Table 2. Plasmids used in this study

\begin{tabular}{|c|c|c|c|}
\hline Name & Description & Background plasmid & Source \\
\hline p416TEF & CEN6, URA3 marker & - & $\operatorname{Ref}^{69}$ \\
\hline p413TEF & CEN6, HIS3 marker & - & $\operatorname{Re}^{69}$ \\
\hline pTEF1-GFP & $\mathrm{P}_{T E F 1}-\mathrm{GFP}$ & p416TEF & $\operatorname{Ref}^{14}$ \\
\hline pCUP1-GFP & $\mathrm{P}_{C U P I}-\mathrm{GFP}$ & p413TEF & This study \\
\hline pCUP1-FadR & $\mathrm{P}_{C U P 1}-\mathrm{FadR}$ & p413TEF & This study \\
\hline pSensor01 & $\mathrm{P}_{T E F I^{-1 B S-G F P}}$ & pTEF1-GFP & This study \\
\hline pSensor02 & $\mathrm{P}_{T E F 1}-2 \mathrm{BS} \_\mathrm{I}-\mathrm{GFP}$ & pTEF1-GFP & This study \\
\hline pSensor03 & $\mathrm{P}_{T E F 1}-2 \mathrm{BS} \_$II-GFP & pTEF1-GFP & This study \\
\hline pSensor04 & $\mathrm{P}_{T E F T^{-}}-3 \mathrm{BS}-\mathrm{GFP}$ & pTEF1-GFP & This study \\
\hline pSensor05 & $\mathrm{P}_{T E F I^{-}}$-3BS-GFP_P $\mathrm{P}_{C U P I}-\mathrm{f} a d R$ & pCUP1-FadR & This study \\
\hline pAmFAR & $\mathrm{P}_{P G K I}-A m F A R$ & p416TEF & This study \\
\hline pMaFAR & $\mathrm{P}_{P G K I}-M a F A R$ & p416TEF & This study \\
\hline pQC005 & $2 \mu \mathrm{m}$ ampR KIURA3 gRNA-CAN1.Y & pMEL10 $0^{63}$ & Lab collection \\
\hline
\end{tabular}

Table 3. Strains used in this study

\begin{tabular}{|c|c|c|}
\hline Strain & Genotype & $\begin{array}{l}\text { Source } \\
\end{array}$ \\
\hline CEN.PK113-11C & MATa SUCMAL2-8c his3A1 ura3-52 & $\operatorname{Ref}^{62}$ \\
\hline IMX581 & MATa ura3-52 can1 $1:$ :cas9-natNT2 TRP1 LEU2 HIS3 & $\operatorname{Re}^{63}$ \\
\hline YDA001 & IMX581; X_3::ACP1 & This study \\
\hline YDA002 & IMX581; X_3::EPT1 & This study \\
\hline YDA003 & IMX581; X_3::FAA1 & This study \\
\hline YDA004 & IMX581; X_3::FAA3 & This study \\
\hline YDA005 & IMX581; X_3::GEP4 & This study \\
\hline YDA006 & IMX581; X_3::GGA2 & This study \\
\hline YDA007 & IMX581; X_3::IDP3 & This study \\
\hline YDA008 & IMX581; X_3::INP54 & This study \\
\hline YDA009 & IMX581; X_3::LPP1 & This study \\
\hline YDA010 & IMX581; X_3::MCR1 & This study \\
\hline YDA011 & IMX581; X_3::MPP6 & This study \\
\hline YDA012 & IMX581; X_3::ORM1 & This study \\
\hline YDA013 & IMX581; X_3::RTC3 & This study \\
\hline YDA014 & IMX581; X_3::SPO7 & This study \\
\hline YDA015 & IMX581; X_3::TGL1 & This study \\
\hline YDA016 & IMX581; X 3::YFT2 & This study \\
\hline
\end{tabular}

\section{Flow Cytometry Measurements and Fluorescence-Activated Cell Sorting}

For flow cytometry analysis, a Guava easyCyte $8 \mathrm{HT}$ system (Merck Millipore) with a blue laser $(488 \mathrm{~nm})$ was used. All samples were, prior to analysis, diluted in water to an $\mathrm{OD}_{600}$ of 0.02 in final volume of $200 \mu \mathrm{l}$. The mean fluorescence intensity of 5000 cells were measured, and FlowJoX software was used for analyzing the data and creating the histogram images. 
FACS was performed using a BD Biosciences Aria (Becton Dickinson) with a blue laser $(488 \mathrm{~nm})$. Cells were, prior to sorting, gated based on the FSC and SSC channels. Gates were set to enrich for cells with high GFP intensity, and sorting was done on purity and four-way sorts with at least 10,000 cells per bin. Sorted cells were recovered in minimal medium with added $\mathrm{Cu}^{2+}$ and grown for at least $18 \mathrm{~h}$ at $30^{\circ} \mathrm{C}$ and subjected to a second round of sorting.

\section{Library sequencing}

Plasmids were extracted from the enriched yeast cells using Zymoprep Yeast Plasmid Miniprep Kits (Zymo Research) (non-purified plasmids). These plasmids were further purified using a Plasmid Purification Kit (Thermo Fisher Scientific) (purified plasmids). The non-purified and purified plasmids were subjected to PCR to amplify the uptag and downtag regions using primer pairs pFDA21/22 and pFDA23/24 as described in detail elsewhere ${ }^{32}$. Sequencing was performed using MiSeq using Eurofins/GATC sequencing service. Resulting data were matched with the MoBY-ORF library and further analyzed (see below).

\section{Quantification of fatty acids}

Fatty acid quantification was based on a method described previously ${ }^{70}$. Briefly, $10 \mathrm{~mL}$ and 5 $\mathrm{mL}$ were harvested from main cultures after $8 \mathrm{~h}$ and $48 \mathrm{~h}$, respectively, and centrifuged for 5 min at $1000 \mathrm{~g}$. After freeze drying the cell pellets for $48 \mathrm{~h}, 10 \mathrm{mg}$ biomass was collected in extraction tubes. The internal standard, heptadecanoic acid (C17:0), was added to all samples before adding the extraction solvent, which consisted of $1 \mathrm{~mL}$ hexane and $2 \mathrm{~mL}$ of $14 \% \mathrm{BF}_{3}$ in $\mathrm{MeOH}$. To remove air, samples were flushed with $\mathrm{N}_{2}$ gas for $30 \mathrm{~s}$ and thereafter vortexed for $20 \mathrm{~s}$. Transesterification was performed through microwave-assisted extraction, employing the following temperature program: heating from room temperature to $120^{\circ} \mathrm{C}$ (within $6 \mathrm{~min}$ ) and kept constant for $5 \mathrm{~min}$. After cooling down to room temperature, $2 \mathrm{~mL}$ Milli-Q (MQ) water was added to the samples, which were subsequently vortexed for $20 \mathrm{~s}$ and centrifuged for $5 \mathrm{~min}$ at $2000 \mathrm{~g}$. The upper phase, or the hexane phase, containing the fatty acid methyl esters (FAMEs), was transferred to $\mathrm{GC}$ glass vials and kept at $-20^{\circ} \mathrm{C}$. All samples were diluted $10 \mathrm{x}$ in hexane prior to analysis by gas chromatography (GC; Focus GC, Thermo Fisher Scientific, USA), equipped with a Zebron ZB-5MS GUARDIAN capillary column (30 $\mathrm{m} \times 0.25 \mathrm{~mm} \times$ $0.25 \mu \mathrm{m}$, Phenomenex) and a DSQII mass spectrometer (Thermo Fischer Scientific). The inlet temperature was set to $240^{\circ} \mathrm{C}$, and the helium (carrier) gas flow to $0.6 \mathrm{~mL} / \mathrm{min}$. The following GC program was applied; initial temperature of $50^{\circ} \mathrm{C}$, hold for $1.5 \mathrm{~min}$; ramp to $220^{\circ} \mathrm{C}$ at a rate of $25^{\circ} \mathrm{C} / \mathrm{min}$; ramp to $240^{\circ} \mathrm{C}$ at a rate of $1.5^{\circ} \mathrm{C} / \mathrm{min}$; ramp to $255^{\circ} \mathrm{C}$ at a rate of $10^{\circ} \mathrm{C} / \mathrm{min}$ and hold for $3 \mathrm{~min}$. The mass transfer line was set to $250^{\circ} \mathrm{C}$, the ion source temperature to $230^{\circ} \mathrm{C}$ and a full scan of 50-650 m/z was performed. Final quantification was performed with Xcalibur software.

\section{Quantification of fatty alcohols}

Fatty alcohol quantification was based on a method described previously ${ }^{71}$. Briefly, $5 \mathrm{~mL}$ cultures were harvested from main cultures after $72 \mathrm{~h}$, and centrifuged for $5 \mathrm{~min}$ at $1000 \mathrm{~g}$. After freeze drying the cell pellets for $72 \mathrm{~h}, 10 \mathrm{mg}$ biomass was collected in extraction tubes. The extraction solvent, consisting of $4 \mathrm{~mL}$ chloroform-methanol $(2: 1 \mathrm{v} / \mathrm{v})$, and the internal standard pentadecanol $\left(\mathrm{C}_{15}-\mathrm{OH}\right)$ were added to the samples and vortexed vigorously for $20 \mathrm{~s}$. 
The temperature program for microwave-assisted extraction was increased to $60^{\circ} \mathrm{C}$ (within 6 $\mathrm{min})$ and kept constant for $10 \mathrm{~min}$. After cooling down to room temperature, $1 \mathrm{~mL} \mathrm{NaCl}(0.73 \%$ $\mathrm{w} / \mathrm{v}$ ) was added and the samples were vortexed vigorously for $20 \mathrm{~s}$. Subsequently, the samples were centrifuged at $1000 \mathrm{~g}$ for $10 \mathrm{~min}$ allowing for phase separation to occur. The organic phase (lower part) was transferred into new extraction tubes and fully dried by rotary evaporation at $40^{\circ} \mathrm{C}$. The samples were derivatized with $100 \mu \mathrm{L}$ BSTFA at $80^{\circ} \mathrm{C}$ for $30 \mathrm{~min}$, and thereafter $100 \mu \mathrm{L}$ ethyl acetate were added. The BSTFA treatment was performed on the same day the samples were quantified on a DSQII mass spectrometer (Thermo Fischer Scientific) or on a GC-FID system (Thermo Fischer Scientific). The inlet temperature was set to $300^{\circ} \mathrm{C}$, and the helium (carrier) gas flow to $1 \mathrm{~mL} / \mathrm{min}$. The program for fatty alcohol quantification was as follows: initial temperature of $50^{\circ} \mathrm{C}$, hold for $2.5 \mathrm{~min}$; ramp to $230^{\circ} \mathrm{C}$ at a rate of $15^{\circ} \mathrm{C} / \mathrm{min}$ and hold for $2 \mathrm{~min}$; ramp to $325^{\circ} \mathrm{C}$ at a rate of $25^{\circ} \mathrm{C} / \mathrm{min}$ and hold for $4 \mathrm{~min}$. The mass transfer line was set to $300^{\circ} \mathrm{C}$, the ion source temperature to $200^{\circ} \mathrm{C}$ and a full scan of $50-650 \mathrm{~m} / \mathrm{z}$ was performed. Final quantification was performed with Xcalibur software.

\section{Data analysis}

All data were analyzed and generated in R studio. To analyze the enriched libraries, the libraries were first sequenced as described under Library sequencing. Sequencing of each enrichment step generated four data sets (up- and downtag for both purified and non-purified libraries), meaning that in total eight data sets were generated considering the two enrichment steps. Here, we will only describe the analysis of enrichment 1 as the exact same approach was performed for enrichment 2.

First, the sequenced libraries were evaluated by normalizing the reads of each gene to the total number of reads in that particular dataset (in ppm). Second, the relative difference (in \%) of the up- and downtag for each gene was calculated, as follows, for both the purified and nonpurified dataset.

Relative difference (uptag, downtag) $(\%)=\frac{\mid \text { uptag }- \text { downtag } \mid}{\max (\text { uptag, downtag) }} \cdot 100$

Although there were no substantial differences between the purified and non-purified libraries, the relative difference for each gene in the purified and non-purified dataset was compared and the one with the smallest difference was chosen for further analysis. Third, since the difference in up- and downtag sometimes differed substantially, the maximum value for each gene was chosen as a representative of the gene occurrence and normalized (in ppm) to the total number of reads for all genes chosen in step 2. The same analysis was performed for the datasets in enrichment 2, and the final dataset was plotted against the dataset from enrichment 1. A cutoff of genes having less than 10 reads in both enrichment steps was used.

GO-term comparison was performed on the enriched libraries using the online tool SGD Gene Ontology Slim Mapper with focus on biological processes. Each biological process that was not enriched was excluded. Furthermore, genes mainly involved in transcriptional and translational processes were also excluded. Genes involved in lipid metabolic processes, lipid transport, response to oxidative stress and Golgi vesicle transport were analyzed further. From 
these processes, the genes with the highest read counts were chosen as candidate genes boosting acyl-CoA levels.

\section{ASSOCIATED CONTENT Supporting Information}

Evaluation of different $\mathrm{Cu}^{2+}$ concentrations, Sorting strategy, GO-term comparison, growth curves, growth rates in both glucose- and ethanol phase, diauxic shift duration of candidate genes, composition (\%) of fatty acids, evaluation of fatty acyl-CoA reductase enzymes (AmFAR and MaFAR), composition (\%) of fatty alcohols and C18/C16 ratio (Figures S1-S8); candidate genes chosen (Table S1); primers used in this study (Table S2); sequences.

\section{ACKNOWLEDGEMENTS}

This work was funded by the Novo Nordisk Foundation (grant no. NNF10CC1016517) and the Ångpanneföreningens Forskningsstiftelse, Sweden. In addition, this project has received funding from the European Union's Horizon 2020 Framework Programme for Research and Innovation - Grant Agreement No. 720824. We would like to thank the Novo Nordisk Foundation Center for Biosustainability (DTU Biosustain, Denmark) for permitting us to use their FACS instrument and Michael Krogh Jensen and Mari Cristina Rodriguez de Evgrafov for support and help during our stay. We would also like to thank Charles Boone (University of Toronto) for providing the MoBY-ORF library. We also appreciate the fruitful discussions with Yi Liu, Kate Campbell and Tao Yu. We also thank Leonie Wenning for providing the yeast codon optimized MaFAR gene and Quanli Liu for providing the gRNA plasmid pQC005.

\section{AUTHOR INFORMATION}

\section{Author contribution}

F.D., V.S., and Y.D., designed the research; F.D., constructed the biosensors and performed the FACS sorting; Y.D., constructed the strains, Y.D., and P.G.T performed the fatty acid- and alcohol measurements; Y.D., P.G.T, and F.D., analyzed the data; Y.D., V.S., F.D., and J.N., prepared the manuscript.

\section{*Corresponding Authors}

Florian David (davidfl@chalmers.se)

Verena Siewers_(siewers@chalmers.se)

\section{NOTES}

\section{Competing interests}

F.D., V.S. and J.N. have filed a patent ('Fungal cells and methods for production of very long chain fatty acid derived products', number PCT /SE2016/05027 4) for protection of part of the work described herein. F.D., J.N., and V.S., are shareholders in Biopetrolia AB. All other authors declare no competing financial interests. 


\section{REFERENCES}

[1] Nielsen, J., and Keasling, J. D. (2016) Engineering Cellular Metabolism, Cell 164, 1185 1197.

[2] Keasling, J. D. (2012) Synthetic biology and the development of tools for metabolic engineering, Metab. Eng. 14, 189-195.

[3] Chae, T. U., Choi, S. Y., Kim, J. W., Ko, Y. S., and Lee, S. Y. (2017) Recent advances in systems metabolic engineering tools and strategies, Curr. Opin. Biotech. 47, 67-82.

[4] Yu, T., Dabirian, Y., Liu, Q., Siewers, V., and Nielsen, J. (2019) Strategies and challenges for metabolic rewiring, Curr. Opin. Syst. Biol. 15, 30-38.

[5] Anderson, M. J., Barker, S. L., Boone, C., and Measday, V. (2012) Identification of RCN1 and RSA3 as ethanol-tolerant genes in Saccharomyces cerevisiae using a high copy barcoded library, FEMS Yeast. Res. 12, 48-60.

[6] Wang, H. H., Isaacs, F. J., Carr, P. A., Sun, Z. Z., Xu, G., Forest, C. R., and Church, G. M. (2009) Programming cells by multiplex genome engineering and accelerated evolution, Nature 460, 894.

[7] Zhang, Y.-X., Perry, K., Vinci, V. A., Powell, K., Stemmer, W. P. C., and del Cardayré, S. B. (2002) Genome shuffling leads to rapid phenotypic improvement in bacteria, Nature 415,644 .

[8] Dietrich, J. A., McKee, A. E., and Keasling, J. D. (2010) High-throughput metabolic engineering: advances in small-molecule screening and selection, Annu. Rev. Biochem. 79, 563-590.

[9] Rogers, J. K., Taylor, N. D., and Church, G. M. (2016) Biosensor-based engineering of biosynthetic pathways, Curr. Opin. Biotech. 42, 84-91.

[10] De Paepe, B., Peters, G., Coussement, P., Maertens, J., and De Mey, M. (2017) Tailormade transcriptional biosensors for optimizing microbial cell factories, J. Ind. Microbiol. Biotechnol. 44, 623-645.

[11] Herrgard, M. J., Covert, M. W., and Palsson, B. O. (2004) Reconstruction of microbial transcriptional regulatory networks, Curr. Opin. Biotech. 15, 70-77.

[12] Skjoedt, M. L., Snoek, T., Kildegaard, K. R., Arsovska, D., Eichenberger, M., Goedecke, T. J., Rajkumar, A. S., Zhang, J., Kristensen, M., Lehka, B. J., Siedler, S., Borodina, I., Jensen, M. K., and Keasling, J. D. (2016) Engineering prokaryotic transcriptional activators as metabolite biosensors in yeast, Nat. Chem. Biol. 12, 951-958.

[13] Xu, P., Li, L., Zhang, F., Stephanopoulos, G., and Koffas, M. (2014) Improving fatty acids production by engineering dynamic pathway regulation and metabolic control, Proc. Natl. Acad. Sci. U.S.A. 111, 11299-11304.

[14] David, F., Nielsen, J., and Siewers, V. (2016) Flux Control at the Malonyl-CoA Node through Hierarchical Dynamic Pathway Regulation in Saccharomyces cerevisiae, ACS Synth. Biol. 5, 224-233.

[15] Li, S., Si, T., Wang, M., and Zhao, H. (2015) Development of a Synthetic Malonyl-CoA Sensor in Saccharomyces cerevisiae for Intracellular Metabolite Monitoring and Genetic Screening, ACS Synth. Biol. 4, 1308-1315.

[16] Teo, W. S., Hee, K. S., and Chang, M. W. (2013) Bacterial FadR and synthetic promoters function as modular fatty acid sensor- regulators in Saccharomyces cerevisiae, Eng. Life Sci. 13, 456-463. 
[17] Zhang, F., Carothers, J. M., and Keasling, J. D. (2012) Design of a dynamic sensorregulator system for production of chemicals and fuels derived from fatty acids, Nature Biotechnol. 30, 354-359.

[18] Zhou, Y. J., Kerkhoven, E. J., and Nielsen, J. (2018) Barriers and opportunities in biobased production of hydrocarbons, Nat. Energy 3, 925-935.

[19] Klug, L., and Daum, G. (2014) Yeast lipid metabolism at a glance, FEMS Yeast Res.14, 369-388.

[20] Faergeman, N. J., and Knudsen, J. (1997) Role of long-chain fatty acyl-CoA esters in the regulation of metabolism and in cell signalling, Biochem. J. 323 ( Pt 1), 1-12.

[21] Bergenholm, D., Gossing, M., Wei, Y., Siewers, V., and Nielsen, J. (2018) Modulation of saturation and chain length of fatty acids in Saccharomyces cerevisiae for production of cocoa butter-like lipids, Biotechnol. Bioeng. 115, 932-942.

[22] Teixeira, P. G., Ferreira, R., Zhou, Y. J., Siewers, V., and Nielsen, J. (2017) Dynamic regulation of fatty acid pools for improved production of fatty alcohols in Saccharomyces cerevisiae, Microb. Cell Fact. 16, 45.

[23] Zhou, Y. J., Buijs, N. A., Zhu, Z., Gómez, D. O., Boonsombuti, A., Siewers, V., and Nielsen, J. (2016) Harnessing Yeast Peroxisomes for Biosynthesis of Fatty-AcidDerived Biofuels and Chemicals with Relieved Side-Pathway Competition, J. Am. Chem. Soc. 138, 15368-15377.

[24] Bergman, A., Vitay, D., Hellgren, J., Chen, Y., Nielsen, J., and Siewers, V. (2019) Effects of overexpression of STB5 in Saccharomyces cerevisiae on fatty acid biosynthesis, physiology and transcriptome, FEMS Yeast Res. 19.

[25] Shi, S., Ji, H., Siewers, V., and Nielsen, J. (2016) Improved production of fatty acids by Saccharomyces cerevisiae through screening a cDNA library from the oleaginous yeast Yarrowia lipolytica, FEMS Yeast Res.16, fov108.

[26] Henry, M. F., and Cronan, J. E. (1991) Escherichia coli transcription factor that both activates fatty acid synthesis and represses fatty acid degradation, J. Mol. Biol. 222, 843-849.

[27] Henry, M. F., and Cronan, J. E., Jr. (1992) A new mechanism of transcriptional regulation: release of an activator triggered by small molecule binding, Cell 70, 671-679.

[28] Kalderon, D., Roberts, B. L., Richardson, W. D., and Smith, A. E. (1984) A short amino acid sequence able to specify nuclear location, Cell 39, 499-509.

[29] DiRusso, C. C., Heimert, T. L., and Metzger, A. K. (1992) Characterization of FadR, a global transcriptional regulator of fatty acid metabolism in Escherichia coli. Interaction with the fadB promoter is prevented by long chain fatty acyl coenzyme A, J. Biol. Chem. 267, 8685-8691.

[30] Peng, B., Williams, T. C., Henry, M., Nielsen, L. K., and Vickers, C. E. (2015) Controlling heterologous gene expression in yeast cell factories on different carbon substrates and across the diauxic shift: a comparison of yeast promoter activities, Microb. Cell Fact. $14,91$.

[31] Ho, C. H., Magtanong, L., Barker, S. L., Gresham, D., Nishimura, S., Natarajan, P., Koh, J. L. Y., Porter, J., Gray, C. A., Andersen, R. J., Giaever, G., Nislow, C., Andrews, B., Botstein, D., Graham, T. R., Yoshida, M., and Boone, C. (2009) A molecular barcoded 
yeast ORF library enables mode-of-action analysis of bioactive compounds, Nature Biotechnol. 27, 369-377.

[32] Smith, A. M., Heisler, L. E., St Onge, R. P., Farias-Hesson, E., Wallace, I. M., Bodeau, J., Harris, A. N., Perry, K. M., Giaever, G., Pourmand, N., and Nislow, C. (2010) Highlymultiplexed barcode sequencing: an efficient method for parallel analysis of pooled samples, Nucleic Acids Res. 38, e142.

[33] Brody, S., Oh, C., Hoja, U., and Schweizer, E. (1997) Mitochondrial acyl carrier protein is involved in lipoic acid synthesis in Saccharomyces cerevisiae, FEBS Lett. 408, 217 220.

[34] Hjelmstad, R. H., and Bell, R. M. (1988) The sn-1,2-diacylglycerol ethanolaminephosphotransferase activity of Saccharomyces cerevisiae. Isolation of mutants and cloning of the EPT1 gene, J. Biol. Chem. 263, 19748-19757.

[35] Knoll, L. J., Johnson, D. R., and Gordon, J. I. (1994) Biochemical studies of three Saccharomyces cerevisiae acyl-CoA synthetases, Faa1p, Faa2p, and Faa3p, J. Biol. Chem. 269, 16348-16356.

[36] Osman, C., Haag, M., Wieland, F. T., Brugger, B., and Langer, T. (2010) A mitochondrial phosphatase required for cardiolipin biosynthesis: the PGP phosphatase Gep4, EMBO J. 29, 1976-1987.

[37] Demmel, L., Gravert, M., Ercan, E., Habermann, B., Müller-Reichert, T., Kukhtina, V., Haucke, V., Baust, T., Sohrmann, M., Kalaidzidis, Y., Klose, C., Beck, M., Peter, M., and Walch-Solimena, C. (2008) The clathrin adaptor Gga2p is a phosphatidylinositol 4phosphate effector at the Golgi exit, Mol. Biol. Cell 19, 1991-2002.

[38] Henke, B., Girzalsky, W., Berteaux-Lecellier, V., and Erdmann, R. (1998) IDP3 encodes a peroxisomal NADP-dependent isocitrate dehydrogenase required for the betaoxidation of unsaturated fatty acids, J. Biol. Chem. 273, 3702-3711.

[39] Wiradjaja, F., Ooms, L. M., Whisstock, J. C., McColl, B., Helfenbaum, L., Sambrook, J. F., Gething, M. J., and Mitchell, C. A. (2001) The yeast inositol polyphosphate 5phosphatase Inp54p localizes to the endoplasmic reticulum via a C-terminal hydrophobic anchoring tail: regulation of secretion from the endoplasmic reticulum, $J$. Biol. Chem. 276, 7643-7653.

[40] Toke, D. A., Bennett, W. L., Oshiro, J., Wu, W. I., Voelker, D. R., and Carman, G. M. (1998) Isolation and characterization of the Saccharomyces cerevisiae LPP1 gene encoding a Mg2+-independent phosphatidate phosphatase, J. Biol. Chem. 273, 1433114338.

[41] Hahne, K., Haucke, V., Ramage, L., and Schatz, G. (1994) Incomplete arrest in the outer membrane sorts NADH-cytochrome b5 reductase to two different submitochondrial compartments, Cell 79, 829-839.

[42] Milligan, L., Decourty, L., Saveanu, C., Rappsilber, J., Ceulemans, H., Jacquier, A., and Tollervey, D. (2008) A Yeast Exosome Cofactor, Mpp6, Functions in RNA Surveillance and in the Degradation of Noncoding RNA Transcripts, Mol. Cell. Biol. $28,5446$.

[43] Han, S., Lone, M. A., Schneiter, R., and Chang, A. (2010) Orm1 and Orm2 are conserved endoplasmic reticulum membrane proteins regulating lipid homeostasis and protein quality control, Proc. Natl. Acad. Sci. U.S.A. 107, 5851. 
[44] Addinall, S. G., Downey, M., Yu, M., Zubko, M. K., Dewar, J., Leake, A., Hallinan, J., Shaw, O., James, K., Wilkinson, D. J., Wipat, A., Durocher, D., and Lydall, D. (2008) A genomewide suppressor and enhancer analysis of cdc13-1 reveals varied cellular processes influencing telomere capping in Saccharomyces cerevisiae, Genetics 180, 2251-2266.

[45] Siniossoglou, S., Santos-Rosa, H., Rappsilber, J., Mann, M., and Hurt, E. (1998) A novel complex of membrane proteins required for formation of a spherical nucleus, EMBOJ. 17, 6449-6464.

[46] Koffel, R., Tiwari, R., Falquet, L., and Schneiter, R. (2005) The Saccharomyces cerevisiae YLL012/YEH1, YLR020/YEH2, and TGL1 genes encode a novel family of membraneanchored lipases that are required for steryl ester hydrolysis, Mol. Cell Biol. 25, 16551668 .

[47] Moir, R. D., Gross, D. A., Silver, D. L., and Willis, I. M. (2012) SCS3 and YFT2 Link Transcription of Phospholipid Biosynthetic Genes to ER Stress and the UPR, PLOS Genet. 8, e1002890.

[48] Teerawanichpan, P., Robertson, A. J., and Qiu, X. (2010) A fatty acyl-CoA reductase highly expressed in the head of honey bee (Apis mellifera) involves biosynthesis of a wide range of aliphatic fatty alcohols, Insect Biochem. Mol. Biol. 40, 641-649.

[49] Hofvander, P., Doan, T. T., and Hamberg, M. (2011) A prokaryotic acyl-CoA reductase performing reduction of fatty acyl-CoA to fatty alcohol, FEBS Lett. 585, 3538-3543.

[50] Shanmuganathan, A., Avery, S. V., Willetts, S. A., and Houghton, J. E. (2004) Copperinduced oxidative stress in Saccharomyces cerevisiae targets enzymes of the glycolytic pathway, FEBS Lett. 556, 253-259.

[51] De Smet, C. H., Vittone, E., Scherer, M., Houweling, M., Liebisch, G., Brouwers, J. F., and de Kroon, A. I. P. M. (2012) The yeast acyltransferase Sct1p regulates fatty acid desaturation by competing with the desaturase Ole1p, Mol. Biol. Cell 23, 1146-1156.

[52] Savchenko, A., Krogan, N., Cort, J. R., Evdokimova, E., Lew, J. M., Yee, A. A., SanchezPulido, L., Andrade, M. A., Bochkarev, A., Watson, J. D., Kennedy, M. A., Greenblatt, J., Hughes, T., Arrowsmith, C. H., Rommens, J. M., and Edwards, A. M. (2005) The Shwachman-Bodian-Diamond syndrome protein family is involved in RNA metabolism, J. Biol. Chem. 280, 19213-19220.

[53] Bonifacino, J. S. (2004) The GGA proteins: adaptors on the move, Nat. Rev. Mol. Cell Biol. 5, 23-32.

[54] Mayinger, P. (2009) Regulation of Golgi function via phosphoinositide lipids, Sem. Cell Dev. Biol. 20, 793-800.

[55] Daboussi, L., Costaguta, G., Ghukasyan, R., and Payne, G. S. (2017) Conserved role for Gga proteins in phosphatidylinositol 4-kinase localization to the trans-Golgi network, Pro. Natl. Acad. Sci. U.S.A. 114, 3433-3438.

[56] Demmel, L., Gravert, M., Ercan, E., Habermann, B., Muller-Reichert, T., Kukhtina, V., Haucke, V., Baust, T., Sohrmann, M., Kalaidzidis, Y., Klose, C., Beck, M., Peter, M., and Walch-Solimena, C. (2008) The clathrin adaptor Gga2p is a phosphatidylinositol 4phosphate effector at the Golgi exit, Mol. Biol. Cell 19, 1991-2002.

[57] Daboussi, L., Costaguta, G., and Payne, G. S. (2012) Phosphoinositide-mediated clathrin adaptor progression at the trans-Golgi network, Nat. Cell Biol. 14, 239-248. 
[58] Henry, S. A., Gaspar, M. L., and Jesch, S. A. (2014) The response to inositol: Regulation of glycerolipid metabolism and stress response signaling in yeast, Chem. Phys. Lipids 180, 23-43.

[59] Ferreira, R., Teixeira, P. G., Siewers, V., and Nielsen, J. (2018) Redirection of lipid flux toward phospholipids in yeast increases fatty acid turnover and secretion, Proc. Natl. Acad. Sci. U.S.A. 115, 1262.

[60] Leber, C., Polson, B., Fernandez-Moya, R., and Da Silva, N. A. (2015) Overproduction and secretion of free fatty acids through disrupted neutral lipid recycle in Saccharomyces cerevisiae, Metab. Eng 28, 54-62.

[61] Valle-Rodríguez, J. O., Shi, S., Siewers, V., and Nielsen, J. (2014) Metabolic engineering of Saccharomyces cerevisiae for production of fatty acid ethyl esters, an advanced biofuel, by eliminating non-essential fatty acid utilization pathways, Appl. Energ. 115, 226-232.

[62] van Dijken, J. P., Bauer, J., Brambilla, L., Duboc, P., Francois, J. M., Gancedo, C., Giuseppin, M. L. F., Heijnen, J. J., Hoare, M., Lange, H. C., Madden, E. A., Niederberger, P., Nielsen, J., Parrou, J. L., Petit, T., Porro, D., Reuss, M., van Riel, N., Rizzi, M., Steensma, H. Y., Verrips, C. T., Vindeløv, J., and Pronk, J. T. (2000) An interlaboratory comparison of physiological and genetic properties of four Saccharomyces cerevisiae strains, Enzyme Microb. Technol. 26, 706-714.

[63] Mans, R., van Rossum, H. M., Wijsman, M., Backx, A., Kuijpers, N. G., van den Broek, M., Daran-Lapujade, P., Pronk, J. T., van Maris, A. J., and Daran, J. M. (2015) CRISPR/Cas9: a molecular Swiss army knife for simultaneous introduction of multiple genetic modifications in Saccharomyces cerevisiae, FEMS Yeast Res. 15.

[64] Verduyn, C., Postma, E., Scheffers, W. A., and Van Dijken, J. P. (1992) Effect of benzoic acid on metabolic fluxes in yeasts: a continuous-culture study on the regulation of respiration and alcoholic fermentation, Yeast 8, 501-517.

[65] Quan, J., and Tian, J. (2011) Circular polymerase extension cloning for high-throughput cloning of complex and combinatorial DNA libraries, Nat. Protoc. 6, 242.

[66] Jessop-Fabre, M. M., Jakociunas, T., Stovicek, V., Dai, Z., Jensen, M. K., Keasling, J. D., and Borodina, I. (2016) EasyClone-MarkerFree: A vector toolkit for marker-less integration of genes into Saccharomyces cerevisiae via CRISPR-Cas9, Biotechnol. J. $11,1110-1117$.

[67] Zhou, Y. J., Gao, W., Rong, Q., Jin, G., Chu, H., Liu, W., Yang, W., Zhu, Z., Li, G., Zhu, G., Huang, L., and Zhao, Z. K. (2012) Modular pathway engineering of diterpenoid synthases and the mevalonic acid pathway for miltiradiene production, J. Am. Chem. Soc. 134, 3234-3241.

[68] Gietz, R. D., and Schiestl, R. H. (2007) High-efficiency yeast transformation using the LiAc/SS carrier DNA/PEG method, Nat. Protoc. 2, 31-34.

[69] Mumberg, D., Muller, R., and Funk, M. (1995) Yeast vectors for the controlled expression of heterologous proteins in different genetic backgrounds, Gene 156, 119-122.

[70] Khoomrung, S., Chumnanpuen, P., Jansa-ard, S., Nookaew, I., and Nielsen, J. (2012) Fast and accurate preparation fatty acid methyl esters by microwave-assisted derivatization in the yeast Saccharomyces cerevisiae, Appl. Microbiol. Biotechnol. 94, 1637-1646. 
[71] Khoomrung, S., Chumnanpuen, P., Jansa-Ard, S., Stahlman, M., Nookaew, I., Boren, J., and Nielsen, J. (2013) Rapid quantification of yeast lipid using microwave-assisted total lipid extraction and HPLC-CAD, Anal. Chem. 85, 4912-4919. 